\title{
Histopathological Patterns of Renal Biopsies in Children with Various Glomerulopathies in a Tertiary Care Centre
}

\author{
Deepika Hemrajani ${ }^{1}$, Ranjana Solanki ${ }^{2}$, Vijendra K Gupta ${ }^{3}$, Vijay K Chaudhary ${ }^{4}$ \\ ${ }^{1}$ Assistant Professor, ${ }^{2}$ Professor, ${ }^{3 *}$ Resident, ${ }^{4}$ Senior Resident, \\ Department of Pathology, Sawai Man Singh Medical College, Jaipur, Rajasthan, India.
}

\begin{abstract}
Background: To determine the spectrum of renal disease among the paediatric population attending tertiary care hospital and to correlate histopathological findings with the clinical data. Method: All paediatric patients who underwent renal biopsy at our hospital between Jan 2014 to July 2015 were included in the present study. Ultrasound guided percutaneous renal biopsies were performed and evaluated under light morphology and immunofluorescent microscopy.

Results: A total of 60 cases were evaluated. Male: Female Ratio is $1.7: 1$. Most common indication of renal biopsy was steroid resistant nephrotic syndrome (SRNS) 49 cases (81\%), followed by proteinuria with hematuria in 3 cases $(5 \%)$ and 3 cases of acute kidney injury (AKI), 2 cases of nephritic syndrome, 2 case of proteinuria with renal failure and 1 case of unexplained hematuria. Primary glomerular pathology was identified in 56 cases $(93.33 \%)$ and secondary cause was identified in 4 cases (6.67). The common histological pattern in decreasing order of frequency was minimal change disease 24 cases (40\%) followed by FSGS 8 cases (13\%). C3 dominant glomerulonephritis 7 cases (11.67\%), IgA nephropathy 4 cases $(6.67 \%$ ), chronic glomerulosclerosis 3 cases $(5 \%), 3$ cases of diffuse proliferative glomerulonephritis 2 cases each of membranoproliferative glomerulonephritis and post infectious glomerulonephritis, 1 case each of alport syndrome and; 1 case of congenital nephrotic syndrome and one case of diffuse mesangial sclerosis was also identified.
\end{abstract}

\section{INTRODUCTION}

Renal biopsy has revolutionized the study of glomerular diseases to a great extent. It has helped in understanding of renal disorders, allowing a correlation with clinical symptoms and biochemical alterations, helped in assessing the disease activity and provided information to allow decisions on treatment and prognosis.

It still remains a valuable clinical tool and is of particular benefit in nephrotic syndrome, acute kidney injury, systemic diseases associated with renal dysfunction, non nephrotic proteinuria, isolated microscopic hematuria, unexplained chronic kidney disease and familial renal disease. More recent prospective studies have suggested that the renal biopsy identifies a diagnosis different from that predicted on clinical ground in $50 \%$ to $60 \%$ of patients and leads to treatment change in $20 \%$ to $50 \%$ of cases. This is particularly apparent in patients with heavy proteinuria \& AKI, in whom the biopsy findings alter the management in $>80 \%$ of cases. Renal biopsy is now able to provide tissue diagnosis in more than $95 \%$ of cases with a life threatening complication rate of less than $0.1 \%{ }^{1}$ The diagnosis and classification of glomerular disease poses a great
Conclusion: The study highlighted the histological pattern of renal diseases. Minimal change disease was found to be the most common histological pattern in children. We identified two rare primary glomerulopathies in our study, namely congenital nephrotic syndrome and diffuse mesangial sclerosis. C3 dominant glomerulonephritis a recently evolved entity was also picked up on histological evaluation. The spectrum of glomerular disease shows a slight variation from geographical locations.

Key Words: Nephrotic Syndrome, Glomerulopathies, C3 Glomerulonephritis.

\section{${ }^{*}$ Correspondence to:}

Dr. Vijendra K Gupta, Resident, Deptt. of Pathology, SMS

Medical College, Jaipur.

Email: drvkguptaggc@gmail.com

Article History:

Received: 30-04-2016, Revised: 12-05-2016, Accepted: 23-05-2016

\begin{tabular}{|l|c|}
\hline \multicolumn{2}{|c|}{ Access this article online } \\
\hline Website: & Quick Response code \\
www.ijmrp.com & \\
\hline DOI: & \\
10.21276/ijmrp.2016.2.3.040 & \\
\hline
\end{tabular}

challenge to the pathologist owing to its complexity and variety of lesions.

With the help of light and electron microscopy and immunofluorescent examination of renal tissues, the renal pathologists have been able to describe their clinicopatholigical corelation, natural history and pathogenesis. ${ }^{2}$

The present study was conducted with the aim to study the histopathological spectrum of paediatric renal disorders and to ascertain the clinicopatholigical spectrum of various paediatric lesions.

\section{AIMS AND OBJECTIVES}

1) To ascertain the clinicopathological spectrum of various paediatric renal disorders.

2) To study the histopathological pattern of renal diseases in children.

\section{MATERIAL AND METHODS}

All the patients' up to 18 years of age who underwent renal biopsy were included in the study. $(n=60)$. We prospectively analysed 
the nature of renal biopsies in children. Light microscopic and immunofluorescent studies were performed on the formalin fixed and normal saline fixed tissue. The core for light microscopy was studied with H\&E, PAS, Massons trichrome and silver methanmine stains. Additional stains were performed whenever needed.

IF study was done on 5 micron cryostat sections using polyclonal FITC antibodies to $\lg$ G, IgM, IgA, C3, kappa and lambda light chains and were graded on a scale of 0-3.

\section{OBSERVATION AND RESULTS}

All renal biopsies obtained from 60 children were analysed. The age ranged from 45 days to 18 years. The mean age was $9.8+5.4$ years. Most cases were seen in age group $12-18$ years 24 cases (40\%). (Table-1)

The commonest indication of renal biopsy was steroid resistant nephrotic syndrome. 49 cases (81.6\%), followed by acute kidney injury and hematuria with proteinuria. 3 cases each (5\%), followed by 2 cases each of acute nephritic syndrome and proteinuria with renal failure and a single case of unexplained hematuria (1.67\%). (Table2)

Out of 60 cases 56 cases (93.3\%) were of primary glomerular disease and 4 cases (6.66\%) of secondary glomerular disease. (Table3). All the cases of MCD 24 cases (100\%), FSGS 8 cases $(100 \%)$ \& MPGN 2 cases presented with nephrotic syndrome, whereas of the 4 cases of $\lg A$ nephropathy 2 (50\%) presented as Nephrotic syndrome \& remaining 2 (50\%) presented as hematuria with proteinuria.

Two cases of post infectious glomerulonephritis presented as SRNS, 1 case (50\%) and 1 case $(50 \%)$ as acute nephritic syndrome. Three cases of diffuse proliferative glomerulonephritis 1 presented with acute kidney injury and 2 as nephritic syndrome. Cases of congenital onset nephrotic syndrome presented as 1 case $(33.33 \%)$ as nephrotic syndrome, 1 case (33.33\%) as acute kidney injury and 1 case of Alports syndrome (33.33\%) as unexplained proteinuria and hematuria. Out of 3 cases of chronic glomerulosclerosis 1 (33.33\%) presented as SRNS and 2 cases (66.6\%) presented with proteinuria with renal failure.

Seven cases of C3 dominant glomerulonephritis presented with different clinical presentations 4 cases (57.1\%) as SRNS, 1 case each (14.28\%) presented with hematuria and proteinuria, acute nephritic syndrome and acute kidney injury. All the cases of secondary glomerulonephritis, 2cases of lupus nephritis, 1 case of diabetic nephropathy $\& 1$ case of amyloid nephropathy presented as SRNS. (Table 4)

Renal disease frequently affected children in the age group 1218 years (24) and least affected in 0-1 years (02).

Most common indication for biopsy at our center is Steroid resistant nephrotic syndrome (SRNS) 49 (81.67\%) and least common indication is Unexplained Hematuria 01 (1.67\%). Primary glomerular diseases 56 (93.33\%) was more common than secondary glomerular diseases 04 (6.67\%).

Table 1: Age Distribution of Children at the Time of Biopsy ( $n=60)$

\begin{tabular}{lc}
\hline Age in Years & No. of Children \\
\hline $0-1 \mathrm{yr}$ & 2 \\
$1-6 \mathrm{yr}$ & 20 \\
$6-12 \mathrm{yr}$ & 14 \\
$12-18 \mathrm{yr}$ & 24 \\
Total & 60 \\
\hline
\end{tabular}

Table 2: Indication of Renal Biopsy

\begin{tabular}{lcc}
\hline Disease & No. Of Cases $(\mathbf{n}=60)$ & $\%$ \\
\hline SRNS & 49 & 81.67 \\
AKI & 3 & 5 \\
Hematuria with Proteinuria & 03 & 5 \\
Acute Nephritic Syndrome & 02 & 3.33 \\
Proteinuria with Renal Failure & 02 & 3.33 \\
Unexplained Hematuria & 01 & 1.67 \\
Total & 60 & 100 \\
\hline
\end{tabular}

Table 3: Classification of Glomerular disease

\begin{tabular}{lcc}
\hline Disease & No of cases $(\mathbf{n}=\mathbf{6 0})$ & $\%$ \\
\hline Primary glomerular disease & 56 & 93.33 \\
Secondary glomerular disease & 04 & 6.67 \\
\hline
\end{tabular}


Deepika Hemrajani et al. Histopathological Patterns of Renal Biopsies in Children with Various Glomerulopathies

Table 4 Clinicopathological Correlation

\begin{tabular}{|c|c|c|c|c|c|c|c|}
\hline Clinical presentation & SRNS & $\begin{array}{l}\text { Hematuria } \\
\text { with } \\
\text { protienuria }\end{array}$ & $\begin{array}{c}\text { Acute } \\
\text { nephritic } \\
\text { syndrome }\end{array}$ & $\begin{array}{l}\text { Acute } \\
\text { kidney } \\
\text { injury }\end{array}$ & $\begin{array}{c}\text { Protienuria } \\
\text { with renal } \\
\text { failure }\end{array}$ & $\begin{array}{l}\text { Unexplained } \\
\text { hematuria }\end{array}$ & TOTAL \\
\hline Histological presentation & & & & & & & - \\
\hline$M C D$ & 24 & & & & & & 24 \\
\hline FSGS & 8 & & & & & & 8 \\
\hline IgA nephropathy & 2 & 2 & & & & & 4 \\
\hline PIGN & 1 & & 1 & & & & 2 \\
\hline Chronic glomerulosclerosis & 1 & & & & 2 & & 3 \\
\hline C3 dominant & 4 & 1 & 1 & 1 & & & 7 \\
\hline Congenital NS & 1 & & & & & & 1 \\
\hline DMS & & & & 1 & & & 1 \\
\hline Alports syndrome & & & & & & 1 & 1 \\
\hline DPGN & & 2 & & 1 & & & 3 \\
\hline MPGN & 2 & & & & & & 2 \\
\hline Lupus nephritis & 2 & & & & & & 2 \\
\hline Diabetic nephropathy & 1 & & & & & & 1 \\
\hline Amyloid nephropathy & 1 & & & & & & 1 \\
\hline TOTAL & 47 & 5 & 2 & 3 & 2 & 1 & 60 \\
\hline
\end{tabular}

Table 5: Comparison of our study with spectrum of glomerular disease in other studies.

\begin{tabular}{|c|c|c|c|c|c|c|c|}
\hline Variables & $\begin{array}{l}\text { Present } \\
\text { study }\end{array}$ & $\begin{array}{l}\text { Mubarak et } \\
\text { al }(2012)^{10}\end{array}$ & $\begin{array}{l}\text { Printza } N \text { et } \\
\text { al }(2011)^{11}\end{array}$ & $\begin{array}{l}\text { Akhatar et } \\
\text { al (2011) }\end{array}$ & $\begin{array}{l}\text { Daniela Pio et } \\
\text { al }(2010)^{13}\end{array}$ & $\begin{array}{l}\text { K.N.Moorani et } \\
\text { al }(2010)^{14}\end{array}$ & $\begin{array}{c}\text { Fatima Zohara } \\
\text { Souilmi et al } \\
(2015)^{15}\end{array}$ \\
\hline Duration of study & 1yr7 month & 2yr 8 month & $7 \mathrm{yrs}$ & $8 \mathrm{yrs}$ & $12 \mathrm{yrs}$ & 4 yrs 6 month & 4 yrs 6 month \\
\hline $\begin{array}{l}\text { No of biopsy } \\
\text { Age } \\
\text { MCD }\end{array}$ & $\begin{array}{c}60 \\
0-18 \text { yrs } \\
40\end{array}$ & $\begin{array}{c}147 \\
0-16 \text { yrs } \\
23.1\end{array}$ & $\begin{array}{c}81 \\
1-18 \text { Yrs } \\
10\end{array}$ & $\begin{array}{c}415 \\
3-15 \text { yrs } \\
24.09\end{array}$ & $\begin{array}{c}134 \\
1 \text { month-18 yrs } \\
9\end{array}$ & $\begin{array}{c}118 \\
6 \text { month-16 yrs } \\
32.2\end{array}$ & $\begin{array}{c}112 \\
\text { Under } 16 \text { yrs } \\
40.2\end{array}$ \\
\hline FSGS & 13.32 & 38.7 & 15 & 18.3 & 6 & 29.66 & 8 \\
\hline $\mathrm{C}_{3} \mathrm{GP}$ & 11.67 & & & & & & \\
\hline IgA Nephropathy & 6.67 & 0.6 & 13.5 & & 15.7 & & 8 \\
\hline CGS & 5 & & & & & & 0.9 \\
\hline PIGN & 3.33 & & 6 & & & 3.38 & \\
\hline MPGN & 3.33 & & & 11.08 & & 7.62 & 4.5 \\
\hline DPGN & 5.33 & & & & & & \\
\hline DMS & 1.67 & & & & & & \\
\hline Alport syndrome & 1.67 & & 1.5 & 0.48 & 8.33 & & \\
\hline $\begin{array}{l}\text { Congenital } \\
\text { nephrotic } \\
\text { syndrome }\end{array}$ & 1.67 & & & & & & \\
\hline Lupus GN & 3.33 & & 8.5 & 0.96 & 11.36 & 9.32 & 11.6 \\
\hline Diabetic GN & 1.67 & & & & & & \\
\hline Amyloid GN & 1.67 & & & 0.96 & & & \\
\hline
\end{tabular}

\section{DISCUSSION}

This study provides important insight into the spectrum of histopathological patterns in various glomerulonephritis. In our study Primary Glomerular Disease (PGD) was diagnosed in 56 of cases and more common in males $37(66.07 \%)$, biopsy was done more frequently in males than females, which is the same as that reported in study of Choi IJ et al, Rivera Fet al ${ }^{10}$, Briganti EM et al ${ }^{11}$. This probably reflects the fact that chronic renal disease is more common in males.

Secondary Glomerular Disease (SGD) was diagnosed in 4 of the cases $(6.67 \%)$ and more common in females $3(75 \%)$. Similar result were found in study of Fatima Zohara Souilimi et al $(2015)^{8}$.

SRNS is the most common indication in various studies

SRNS is the most common indication $49(81.67 \%)$ for renal biopsy in our study. Similar results were observed in the study of
Edward Saca et al $(2007)^{12} 32.7 \%$, Printza N et al $(2011)^{4} 57 \%$, Reem Hadidi et al $(2014)^{13} 25 \%$, Khatun N et al $(2014)^{14} 24.3 \%$, Dr.Rasim M.Khamass et al $(2015)^{15} 66.7 \%$, Muhammad Arif et al $(2015)^{16} 28.1 \%$.

Unexplained Hematuria is the commonest indication for performing renal biopsy in developed countries as indicated in the study of Coppo R et al (1998)24, Rivera F et al (2002) ${ }^{18}$, Gesualdo $L$ et al (2004) ${ }^{19}$. However it was the least common indication in our study.

MCD is the most common histopathological diagnosis in the paediatric population

Overall, the pattern in our study shows that MCD $(40 \%)$ is the leading cause of PGD. It formed the most common histopathological diagnosis in the paediatric population with renal disease. MCD was the most common cause of idiopathic 
nephrotic syndrome in children. On the other hand, membranous glomerulonephritis was an infrequent finding in children with nephrotic syndrome, unlike that found in adults. This was similarly study by a report of the International Study of Kidney Disease in Children $^{20}$. This is also consistent with the study of K. El- Reshaid et al (1999) 21 41.25\%, J.J Khoo et al (2004)22 40.7\%, Khemchand Netram Moorani et al (2010)14 32.2\%, A.Absar et al (2010)23 37\%, Mohamed B. Abdelraheem et al (2010) 24 29.9\%, Akhtar Ali et al $(2011)^{5}$ 24.09\%, Ahmad Zeb Khan et al (2013) ${ }^{14} 42.66 \%$, Reem Hadidi et al $(2014)^{13} 27 \%$, Pawan Pradeep Mutalik et al (2015) ${ }^{25}$ $33.5 \%$, Fatima Zohara Soulimi et al $(2015)^{8} 40.2 \%$. We did not encounter any case of membranous GN. We observed one case of SRNS with histological and IF findings in favour of Minimal Change disease showing persistent immature glomeruli. The patient was 2.5 years old and foci of immature embryonic type glomeruli may have led to refractory NS. Immature glomeruli are rarely seen in ages up to $5 y$ rs and even in ages 2yrs. Nakamura et al $(2012)^{26}$ reported an $8 \mathrm{yr}$ old girl presenting with refractory nephrotic syndrome whose renal biopsy showed immature embryonic type glomeruli.

\section{FSGS: Comparison of our study from other studies}

FSGS was a less common cause of SRNS in our study (14.29\%), however it was a predominant cause in several others studies by Edward Saca et al (2007)12 19\%, Dusan Paripović et al (2012)27 $20.9 \%$, Muhammed Mubarak et al $(2012)^{3} 38.5 \%$, Khatun $\mathrm{N}$ et al $(2014)^{14} 27.58$, Muhamad Arif et al $(2015)^{16} 29.7 \%$.

The reasons for the discrepancies in the results are not exactly known, but may be related to racial, genetic, or environmental factors. Moreover, slight differences in disease definitions and inclusion criteria may be partly responsible.

\section{IgA Nephropathy}

Four $(6.67 \%)$ cases of IgA nephropathy were detected in our study. However, the prevalence is much higher in study of Yap HK.et al $(1989)^{28} 17 \%$, Daniela Pio et al $(2010)^{6} 15.7 \%$, Printza N et al $(2011)^{4} 13.5$. This could be due to greater population screening and the following biopsy and also related to racial, genetic and environmental factors.

\section{C3 Dominant glomerulonephritis}

Total seven cases (11.67\%) with C3 deposition were observed and reported as C3 dominant glomerulonephritis. It comprised 0.7 $\%$ of all renal biopsies in a study by Viswanathan et al ${ }^{29}$ and 1.16 $\%$ in another study by Mathur et $a^{30}$. This discrepancy could be attributed to small sample size. EM is undoubtedly essential to classify these disorders which is not available in our centre.

The morphological patterns were heterogeneous and ranged from MPGN, DPGN, isolated mesangial hypercellularity and crescentic GN. diagnostic criteria was more than $3+$ staining with $\mathrm{C} 3$ on IF and absence of significant Ig staining or $\mathrm{C} 3$ staining two orders of magnitude more than that of $\lg \mathrm{G}$ or $\operatorname{lgM}$ staining.

Major entities miscalled as C3 GP are auto immune GN and infection related $\mathrm{GN}$. The goal is to identify patients with abnormalities of alternate complement pathway.

The differentiation of true PIGN from C3 GP often cannot be made on the basis of morphology, clinical and lab data available at the time of biopsy. Refining the differential diagnosis will require following the patient clinically and serologically over several months to determine the course of urinary abnormalities and serum C3 level. If these parameters do not follow a typical course of PIGN (that is, normalization of the decreased peripheral C3 level in 8-12 weeks), the diagnosis of C3 GP is considered. Such cases are advised a further workup of electron microscopic study and complement assays in order to differentiate dense deposit disease and C3 Glomerulonephritis. C3 glomerulopathy is a recently evolving entity with a heterogeneous presentation, morphological appearance and outcome and specific therapeutic considerations. ${ }^{31}$ The higher percentage of patients in our cross sectional study could also be attributed to lack of follow up performance of these patients. Evaluation of such cases requires measurement of individual complement factor levels and screening for mutations of complement regulatory proteins. 30 These tests are currently available in research labs only.

\section{Congenital nephrotic syndrome}

Two cases of congenital nephrotic syndrome were found. One of which showed Diffuse Mesangial Sclerosis (DMS) presented with severe proteinuria and marked renal insufficiency in a 45 days old infant. Histologically there was marked podocyte hyperplasia. The nephrotic syndrome develops early in patients with DMS and when present at birth, may be confused with Finish type of congenital nephrotic syndrome. However, its rapid course to end stage renal disease and its characteristic glomerular pathology establishes the diagnosis. Habib and Bois et al reported this entity in nephrotic infants with specific clinical and histological appearance. ${ }^{32}$ There was another case of a one year old child presented with SRNS and histologically showing immature glomeruli with podocyte hyperplasia.

One case of alports syndrome was found in our study in a 10 year old patient presented with unexplained hematuria and typical family history of sensory neural deafness in siblings. Estimated frequency of alport syndrome is 1:500033 It accounts for $1-2 \%$ of end stage renal disease in Europe and in India34.

\section{Renal amyloidosis}

Single case of renal amyloidosis with granulomatous interstitial nephritis was identified. Chronic tuberculosis is often complicated by amyloidosis which is an important cause of renal disease in India.

\section{LN is the commonest cause of SGD in various studies}

$L N$ is the commonest cause of SGD (50\%) among the SGD and contributed for $3.3 \%$ cases in overall biopsies. This is almost similar to study by K.EL-Reshaid et al (1999) ${ }^{21} 44 \%$, Moorani et al $(2010)^{7} 61.11 \%$, Mohamed A Abdelraheem et al (2010) $)^{24} 100 \%$, Daniela Pio et al $(2010)^{6} 43 \%$, Kamel V Kanodia $(2015)^{35}$.

\section{CONCLUSION}

The pattern of renal disease in pediatric age group presented in this study provide an updated epidemiological data from our center. It is comparable with earlier published reports with some differences. There is a need for a national pediatric biopsy registry in India in order to address the regional difference in the spectrum of pediatric glomerular diseases. Biopsy will help in making an early diagnosis and instituting the optimal therapeutic regimen.

\section{LIMITATIONS}

There were few limitations in our study, the sample size was small and hence does not represent exact demographic picture. Due to cost limitations electron microscopy could not be performed. 


\section{REFERENCES}

1. Topham P. (2007). Renal biopsy. In: Feehally J., Floege J. \& Johnson R., editors. Comprehensiveclinical nephrology. 3rd. ed. Philadelphia: Mosby, Elsevier Inc. Ch. 6 p. $69-75$.

2. Habib R. A story of glomerulopathies: a pathologist's experience. Pediatr Nephrol 1993; 7: 336-46.

3. Muhammed Mubarak, Javed I.Kazi, Shaheera Shakeel, Ali Lanewala, and Seema Hashmi. The Spectrum of Histopathological Lesions in Children Presenting with Steroid-Resistant Nephrotic Syndrome at a Single Center in Pakistan. The Scientific World Journal Volume 2012, Article ID 681802, 5 pages.

4. Printza N, Bosdou J, Pantzaki A, Badouraki M, Kollios K, Ghogha Ch, Papachristou F. Percutaneous ultrasound-guided renal biopsy in children: a single centre experience. Hippokratia 2011; 15 (3): 258-261.

5. Akhtar A, Mohammad UA, Sultan ZA.Histological pattern of paediatric renal diseases in Northern Pakistan. JPMA 61:653; 2011.

6.Daniela Pio, Sofia Figueiredo, Pedro Silva, Susana Nunes, Teresa Costa, Elisio in children. A twelve-year review. Port J Nephrol Hypert 2010; 24(3): 215-221.

7. Moorani KM, Sherali AR. Histopathological pattern in childhood glomerulonephritis.JPMA 60:1006; 2010.

8. Fatima Zohra Souilmi, Tarik Sqalli Houssaini, H. Alaoui, T. Harmouch, S. Atmani, M. Hida.Indications and Results of Renal Biopsy in Children: A Single-center Experience from Morocco.Saudi J Kidney Dis Transpl 2015;26(4):810-815.

9. Choi IJ, Jeong HJ, Han DS, et al. An analysis of 4,514 cases of renal biopsy in Korea. Yonsei Med J 2001; 42(2): 247-254.

10. Rivera F, Lopez-Gomez JM, Perez-Garcia R.Spanish registry of glomerulonephritis frequency of renal pathology in Spain 1994-1999. Nephrol Dial Transplant 2002; 17(9): 1594-1602.

11. Briganti EM, Dowling J, Finlay M, et al. The incidence of biopsyproven glomerulonephritis in Australia. Nephrol Dial Transplant 2001; 16(7):1364-1367.

12. Edward Saca MD, Issa Hazza MD, Ola EI-Imam MD, Mona Kawar MD spectrum of biopsy-proven renal disease in the pediatric age group at King Hussein medical center.JRMS April 2007; 14(1): 34-37.

13. Reem Hadidi, May Hadidi, Ma'en alDabbas.Spectrum of Biopsyproven Kidney Disease in Children at a Jordanian Hospital.Saudi J Kidney Dis Transpl 2014;25(3):680-683.

14. Khatun N, Bista KP, Mahaseth C.Spectrum of Biopsy Proven Glomerular Disease in Children at Kanti Children's Hos pital.J Nepal Paediatr Soc 2014;34(3):225-229.

15. Dr. Rasim M. Khamass, Prof. Dr. Mahjoob N. Al-Naddawi.Indications for Renal Biopsy in Iraqi Children With Glomerular Diseases.Volume : 5 | Issue : 7 | July 2015 | ISSN - 2249-555X.

16.Muhammad Arif ,Muhammad Khubaib Arif ,Nida Amjad Pervaiz , Zubair Ahmad.Histopthological Spectrum of Renal Biopsies in Pediatric Population: An Update Nephrotic syndrome in Indian children. Arch Dis Child 1975;50: 62630 .

17. Coppo R, Gianoglio B, Porcellini MG, Maringhini S. Frequency of renal diseases and clinical indications for renal biopsy in children (report of the Italian National Registry of Renal Biopsies in Children). Group of Renal Immunopathology of the Italian Society of Pediatric Nephrology and Group of Renal Immunopathology of the Italian Society of Nephrology. Nephrol Dial Transplant. 1998;13(2):293-297.

18. Rivera F, Lopez-Gomez JM, Perez-Garcia R. Spanish registry of glomerulonephritis frequency of renal pathology in Spain 1994-1999. Nephrol Dial Transplant 2002; 17(9): 1594-1602.

19. Gesualdo L, Di Palma AM, Morrone LF, et al. Italian immunopathology group, Italian Society of Nephrology. The Italian experience of the national registry of renal biopsies. Kidney Int 2004;66(3):890-894.

20. Nephrotic syndrome in children: prediction of histopathology from clinical and laboratory characteristics at time of diagnosis. A report of the International Study of Kidney Disease in Children.1978 Feb;13(2):159-65. 21. K. El-Reshaida M.M. Kapoorb M.R.N. Nampooryb J.P. Maddac N. Jawadd K.V. Johnya. Glomerulonephritis in Children: Experience from the
Kuwait Renal Centers. Med Principles Pract 1999;8:328-333.

22.j J Khoo, MPath, S Pee, MRCP, B Thevarajah, MRCP, Y C Yap, MRCP, C K Chin, MRCP. Biopsy-Proven Childhood Glomerulonephritis in Johor. Med J Malaysia Vol 59 No 2 June 2004.

23. A. Absar, M. Diamond, Y. Sonia, R. Arshalooz, A. Safi a, K. Waqar, P. Shahid.Ten year experience of pediatric kidney biopsies from a single center in Pakistan. Indian Journal of Nephrology. October 2010;20(4).

24.Mohamed B. Abdelraheem, El-Tigani M. A. Ali, Reem M. Mohamed, Einas G. Hassan, Osman A. Abdalla, Salwa O. Mekki, B.M .Yousif,Pattern of Glomerular Diseases in Sudanese Children: a ClinicoPathological Study Alan R Watson.Saudi J Kidney Dis Transpl 2010;21(4):778-783.

25. Pawan Pradeep Mutalik, Subal Kumar Pradhan, Bikrant Kumar Prusty, Kedar Das, Saroj Kumar Satapathy.Clinicopathological correlations of childhood glomerular disease in Eastern India. Sri Lanka Journal of Child Health, 2015; 44(1): 31-37.

26. Taichiro Nakamura,Kazushi Tsuruga,Shojiro Watanabe,Etsuro Ito, Kensuke Joh and Hiroshi Tanaka.Persistent immature glomeruli in a girl with refractory nephrotic syndrome. Nephrology () 2012 Asian Pacific Society of Nephrology.

27. Dušan Paripović , Mirjana Kostić , Divna Kruščić , Brankica Spasojević, Gordana Lomić , Jasmina Marković-Lipkovski , Gordana Basta-Jovanović, Željko Smoljanić , Amira Peco-Antić. Indications and results of renal biopsy in children: a 10-year review from a single center in Serbia. JNEPHROL 2012; 25(06): 1054 -1059.

28. Yap HK, Murugasu B, Saw AH, Chiang GS, Tay JS, Wong HB, Tan $\mathrm{CL}$, Lim $\mathrm{CH}$. Pattern of glomerulonephritis in Singapore children a renal biopsy perspective. 1989 Jan;18(1):359.

29. Ganesh Kumar Viswanathan, Ritambhra Nada, Ashwani Kumar, Raja Ramachandran, Charan Singh Rayat, Vivekanand Jha, Vinay Sakhuja and Kusum Joshi. Clinicopathologic spectrum of C3 glomerulopathy-an Indian experience.Viswanathan et al. Diagnostic Pathology (2015) 10:6.

30. M. Mathur, S. Sharma, D. Prasad, R. Garsa, A. P. Singh, R. Kumar, P. Beniwal, D. Agarwal, and V. Malhotra.Incidence and profile of $\mathrm{C} 3$ Glomerulopathy: A single center study.Indian J Nephrol. 2015;25(1):8-11. 31. Matthew C. Pickering et al (2013) C3 glomerulopathy: consensus report. Kidney International (2013) 84, 1079-1089.

32. Habib R,Gubler MC,Antignac C ,Gagnadoux MF.Diffuse mesangial sclerosis: a congenital glomerulopathy with nephrotic syndrome.Adv Nephrol Necker Hosp 1993;22:43.

33.Atkin CL,Gregory MC, Border WA. Alports syndrome. In: Schrier RW, Gottschalk CW, eds. Diseases of kidney , 4th ed.Boston: Little, Brown and company, 1988:617.

34.Chug KS, Sakhuja V, Agarwal A, et al. Heriditary nephritis(Alports syndrome): Clinical profile and inheritance in 28 Kindreds. Nephro dial Transplant 1993;8:690.

35. Kamal V. Kanodia ,; Aruna V. Vanikar ; Lovelesh K. Nigam ; Rashmi D. Patel ; Kamlesh S. Suthar ; Dinesh N. Gera ; Hargovind L. Trivedi. Pediatric Renal Biopsies in India: A Single-Centre Experience of Six Years. Nephro Urol Mon. 2015 July; 7(4): e25473

\section{Source of Support: Nil. Conflict of Interest: None Declared.}

Copyright: (c) the author(s) and publisher. IJMRP is an official publication of Ibn Sina Academy of Medieval Medicine \& Sciences, registered in 2001 under Indian Trusts Act, 1882.

This is an open access article distributed under the terms of the Creative Commons Attribution Non-commercial License, which permits unrestricted non-commercial use, distribution, and reproduction in any medium, provided the original work is properly cited.

Cite this article as: Deepika Hemrajani, Ranjana Solanki, Vijendra K Gupta, Vijay K Chaudhary. Histopathological Patterns of Renal Biopsies in Children with Various Glomerulopathies in a Tertiary Care Centre. Int J Med Res Prof. 2016; 2(3):183-87. 